\title{
El comercio Sur-Sur y Sur-Norte: ¿cuál contribuye más al desarrollo de Asia y América del Sur? Ideas a partir de la estimación de elasticidades-ingreso de la demanda de importaciones
}

\author{
Thomas Bernhardt
}

RESUMEN

La experiencia de la crisis económica mundial indujo a los países en desarrollo a intensificar la diversificación de las fuentes de crecimiento buscando modelos alternativos de desenvolvimiento económico. La expansión del comercio Sur-Sur se fue afianzando en esta búsqueda. Pero ¿cuán prometedora es esta estrategia? Procurando dar respuesta, aquí se documenta la evolución del comercio Sur-Sur, ofreciendo algunas consideraciones teóricas. Luego se realiza un análisis econométrico para estimar las elasticidades-ingreso de la demanda de importaciones en las relaciones comerciales bilaterales entre países en desarrollo de Asia y América del Sur y dos mercados clave del Norte. Al aplicar un modelo ARDL, el análisis produce variados resultados sobre si el comercio Sur-Sur presenta mayores elasticidades-ingreso que el Sur-Norte, revelándose que el primero puede ser una fuente alternativa de crecimiento, especialmente si persisten las diferencias en el aumento de las importaciones y el ingreso entre el Norte y el Sur. 


\section{I}

\section{Introducción}

El gran colapso registrado en el comercio mundial, tras la reciente crisis económica y financiera internacional, ha puesto en tela de juicio la sostenibilidad del régimen de crecimiento impulsado por las exportaciones imperante en varias economías emergentes y en desarrollo (GriffithJones y Ocampo, 2009; Ocampo, 2009). Tradicionalmente, y también en el pasado reciente, muchos países en desarrollo han centrado sus exportaciones sobre todo en productos primarios y productos derivados de la explotación de recursos naturales, que por lo general han intercambiado por importaciones de manufacturas más intensivas en tecnología y conocimientos especializados provenientes, principalmente, de países ricos del Norte Global (UNCTAD, 2005, pág. 129). Con la última crisis quedó en claro que los países dependientes de las exportaciones deben diversificar sus fuentes de crecimiento, y ello podría incluir la diversificación de los destinos a los que exportan. La intensificación del comercio Sur-Sur - esto es, el comercio entre países en desarrollo- no solo podría servir para salir de la crisis a corto plazo, sino que también, desde una perspectiva a más largo plazo, formar parte de una estrategia de desarrollo más confiable y sostenible para países de más bajos ingresos (Milberg y Winkler, 2010) ${ }^{1}$.

De hecho, algunos de los primeros economistas desarrollistas, como Myrdal (1956) y Lewis (1980), ya habían hecho referencia al potencial del comercio Sur-Sur como impulsor del desenvolvimiento económico. Ellos

$\square$ Gran parte de este trabajo fue escrita mientras el autor se encontraba en la New School for Social Research. Las ideas aquí expresadas le pertenecen y no necesariamente reflejan la visión del Myanmar Development Resource Institute-Centre for Economic and Social Development (MDRI-CESD). Se agradecen los valiosos comentarios de Christian Schoder, Matthias Schnetzer, Manuel Albaladejo, Will Milberg, Christian Proaño, Gary Gereffi y un revisor anónimo que evaluó las primeras versiones de este documento. Todos los errores que pueda haber en este artículo son de entera responsabilidad del autor.

${ }^{1} \mathrm{El}$ "Sur" incluye aquí a todos los países clasificados como economías en desarrollo por la base de datos UNCTADStat. Esto comprende a todos los países del continente africano, todos los países de Asia, excepto Israel, el Japón y los países de la ex Unión Soviética, Oriente Medio y toda América, incluido el Caribe, pero con la excepción de las Bermudas, el Canadá, los Estados Unidos de América, Groenlandia y San Pedro y Miquelón. Véase [en línea] http://unctadstat.unctad.org/ EN/Classifications/DimCountries_DevelopmentStatus_Hierarchy.pdf. destacaron que la integración Sur-Sur podría ayudar a los países en desarrollo a reducir la dependencia de los mercados del Norte y contribuir a superar los cuellos de botella relacionados con las dotaciones de recursos y el tamaño de los mercados internos, promoviendo así la industrialización. Más adelante, algunos académicos — como Amsden (1987) y Lall (1987) — constataron la naturaleza cada vez más industrializada del comercio Sur-Sur, caracterizado por una proporción más alta de productos intensivos en capital y conocimientos especializados, en comparación con las exportaciones hacia el Norte por parte de los países en desarrollo, y vieron en el comercio Sur-Sur de manufacturas sofisticadas un posible catalizador de ganancias dinámicas que ayuda a la industrialización y a la transferencia de tecnología en el Sur (Dahi y Demir, 2008, pág. 267). En los últimos tiempos, diversos organismos de desarrollo internacional, sobre todo pertenecientes al sistema de las Naciones Unidas, han mostrado un renovado interés en la cooperación y el comercio Sur-Sur como vehículo para enfrentar varios de los problemas de desarrollo del mundo y como un camino cada vez más prometedor para alcanzarlo (UNCTAD, 2005, 2010 y 2011; ONUDI, 2006; BASD, 2011; Banco Mundial, 2011; PNUD, 2013, cap. 2).

Ahora bien, ¿cómo reaccionan las cifras del comercio Sur-Sur a los cambios en la actividad económica y en el ingreso en los países en desarrollo involucrados? ¿Cómo se compara lo anterior con las consecuencias de un incremento del ingreso en los países ricos que son sus socios comerciales? ¿Puede el comercio Sur-Sur — sobre la base de estimaciones econométricas de elasticidadesingreso- convertirse en una fuente prometedora de demanda y crecimiento económico en general?

En el presente artículo se intenta responder a estas preguntas analizando el aspecto empírico de ciertos segmentos del comercio Sur-Sur, específicamente del comercio tanto interregional como intrarregional entre las economías de Asia y América del Sur, y comparándolo con el comercio de estos países con representantes del Norte Global rico, en especial la zona del euro y los Estados Unidos de América. En efecto, el estudio tiene por objeto analizar las fuerzas impulsoras, las implicancias y las perspectivas del comercio Sur-Sur como promotor del desarrollo económico. En particular, 
sobre la base de una muestra de las relaciones comerciales entre Asia y América del Sur, se trata de establecer si el comercio Sur-Sur en general se caracteriza por mayores elasticidades-ingreso y es, por lo tanto, una fuente de crecimiento más prometedora que las exportaciones de los países en desarrollo a los países ricos.

Con el propósito de dar cuenta de los cambios en las estructuras del comercio internacional y regional y luego de esta Introducción, en la sección II se lleva a cabo un análisis empírico de la magnitud del comercio Sur-Sur y de cómo este ha evolucionado en las últimas décadas. A continuación, en la sección III, se analiza por qué el comercio Sur-Sur debería resultar beneficioso para los países en desarrollo y hasta qué punto difiere del comercio Norte-Sur. Posteriormente, en la sección IV se investiga específicamente si las elasticidades-ingreso de la demanda de importaciones difieren en su magnitud y sirven como indicador de las perspectivas de que el comercio Sur-Sur se transforme en impulsor del desarrollo económico en Asia y América del Sur. Por su parte, la sección $\mathrm{V}$ se focaliza en el modelo econométrico y el enfoque empírico y en la sección VI se muestran el objetivo del análisis y los resultados de la regresión; en tanto que en la sección VII se efectúa una comparación entre el comercio Sur-Sur y el comercio Sur-Norte, su pasado y futuro. Por último, la sección VIII se refiere a las consecuencias en materia de políticas y en ella se entregan las reflexiones finales.

\section{II}

\section{Análisis empírico del comercio Sur-Sur: magnitud, evolución y patrones}

En esta sección se realiza un breve análisis empírico de la magnitud del comercio Sur-Sur y su evolución en las últimas décadas. También se procura examinar las fuerzas que impulsan ese comercio. ¿Cómo son los flujos del comercio Sur-Sur y cuál es su estructura y composición geográfica?

Inicialmente, se analiza el desempeño exportador general de los países en desarrollo. En el gráfico 1 se muestra la tendencia a largo plazo de las exportaciones provenientes del Sur desde la Segunda Guerra Mundial. Esto revela tres fases bien diferenciadas. Primero, en las dos décadas y media que siguieron a la finalización de ese conflicto bélico, la cuota de exportaciones provenientes del Sur en el comercio mundial se redujo de más del $30 \%$ a menos del $20 \%$. En la segunda fase, dominada por los altos precios de los productos básicos desde mediados de la década de 1970, se registró un marcado incremento de la participación del Sur en las exportaciones mundiales, que se elevó casi al $30 \%$ y se mantuvo sobre el $25 \%$ hasta mediados de los años ochenta, antes de que el descenso en los precios de los productos básicos y el petróleo hiciera que volviera a bajar, llegando al $21 \%$ en 1987. Desde entonces, la cuota de exportaciones del Sur ha experimentado una continua tendencia ascendente y en 2012 alcanzó el récord del 44\% (lo que representa un valor de exportaciones equivalente a 6,14 billones de dólares $)^{2}$. Como se aprecia en el gráfico 1 , esta tendencia ascendente se ha visto impulsada sobre todo por las economías en desarrollo de Asia. Es importante destacar que en la fase actual, que comienza a mediados de los años ochenta, el crecimiento de las exportaciones provenientes de los países en desarrollo ha implicado un alza no solo en los valores del comercio, sino también en los volúmenes. Shirotori y Molina (2009, pág. 2) señalan que el volumen de exportaciones del Sur al mundo se quintuplicó desde los años ochenta, en tanto que las exportaciones mundiales apenas se triplicaron. En promedio, las exportaciones del Sur aumentaron un $7 \%$ anual desde 1980, superando la tasa media de crecimiento anual de las exportaciones mundiales globales (6\%).

Gran parte del aumento de las exportaciones provenientes del Sur puede explicarse por la expansión del comercio Sur-Sur (Hanson, 2012). Esto es especialmente válido para la década recién pasada. En 2011, el total de exportaciones Sur-Sur llegó a 4,3 billones de dólares, el $55 \%$ del total de las exportaciones provenientes del Sur. El pronunciado incremento de las exportaciones Sur-Sur se vuelve evidente cuando estas se comparan con las

\footnotetext{
${ }^{2}$ Las tasas medias de crecimiento anual durante estas tres fases fueron de $6 \%, 14 \%$ y $11 \%$, respectivamente.
} 
GRÁFICO

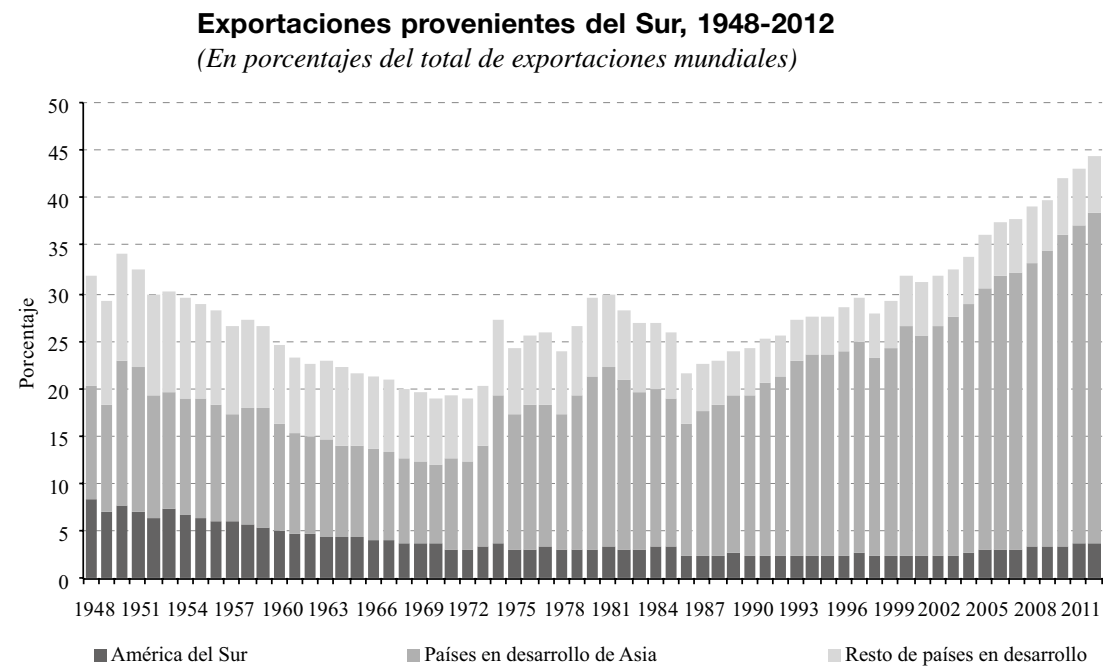

Fuente: Elaboración propia sobre la base de información de la base de datos UNCTADstat.

exportaciones del Sur al resto del mundo. En el gráfico 2 se observa que, entre 1995 y 2011, las exportaciones Sur-Sur registraron un notable crecimiento medio anual del 13\%, muy superior al crecimiento anual del 9,5\% de las exportaciones al resto del mundo. Al comparar estas cifras con datos informados anteriormente por Shirotori y Molina (2009, pág. 3), se constata que la brecha de crecimiento se ha ampliado en los últimos años: en los diez años comprendidos entre 1995 y 2005, las exportaciones de países en desarrollo a otros países en desarrollo aumentaron un promedio anual del 11,5\%, mientras que sus exportaciones al resto del mundo se acrecentaron en un 9,3\% anual. Esto supone una diferencia de crecimiento anual de 2,2 puntos porcentuales, muy inferior a la brecha de crecimiento de 3,5 puntos porcentuales de las exportaciones en el período 2005-2011 $1^{3}$. Como puede apreciarse en el gráfico 2 , este rápido incremento de las exportaciones a mercados del Sur ha sido un fenómeno compartido en todos los continentes: las economías en desarrollo de Asia registraron las tasas de crecimiento anual más elevadas (con un promedio del 13,1\% entre 1995 y 2011), en tanto que los países en desarrollo de África y América están más o menos parejos (rondan el $12,6 \%$ anual).

Existen, no obstante, algunas diferencias regionales en lo que respecta a la gravitación del Sur como mercado exportador. En 2011, los países en desarrollo de Asia

\footnotetext{
${ }^{3}$ Todos los datos incluidos en esta sección se tomaron de la base de datos UNCTADStat [en línea] http://unctadstat.unctad.org.
}

dirigieron bastante más de la mitad de sus exportaciones (59\%) a otros países del Sur Global. Esta proporción fue menor en otras regiones: en África las exportaciones al Sur representaron el $43 \%$ del total y en toda América esta cifra fue del 39\%, mientras que para la subregión de América del Sur la cantidad fue mucho mayor, llegando al $54 \%$.

Hay otros dos aspectos que vale la pena destacar. El primero es que el comercio Sur-Sur está claramente dominado por Asia, que ha actuado como "locomotora del comercio Sur-Sur" (UNCTAD, 2008, pág. 3). En efecto, Asia es - al mismo tiempo- el mayor exportador e importador en el comercio Sur-Sur y sus exportaciones (incluidas las intrarregionales) representaron el $84 \%$ del total del comercio Sur-Sur en 2012. Este predominio puede explicarse por el gran tamaño económico de Asia y también debido a su función como principal núcleo mundial del comercio internacional y su participación mayoritaria en el comercio global en comparación con África y América, las otras dos regiones en desarrollo (Shirotori y Molina, 2009) ${ }^{4}$. En segundo término, el comercio interregional en la actualidad solo constituye una pequeña porción del comercio Sur-Sur, ya que en su mayor parte se lleva a cabo entre países pertenecientes a una misma región. Nuevamente, Asia toma la delantera debido al alto grado de integración regional, que suele concretarse en cadenas regionales de suministro.

\footnotetext{
${ }^{4}$ Muchas redes de producción orientadas a las exportaciones se concentran en Asia, principalmente en China, el Japón y la República de Corea. Este fenómeno se conoce como "fábrica Asia".
} 
GRÁFICO 2

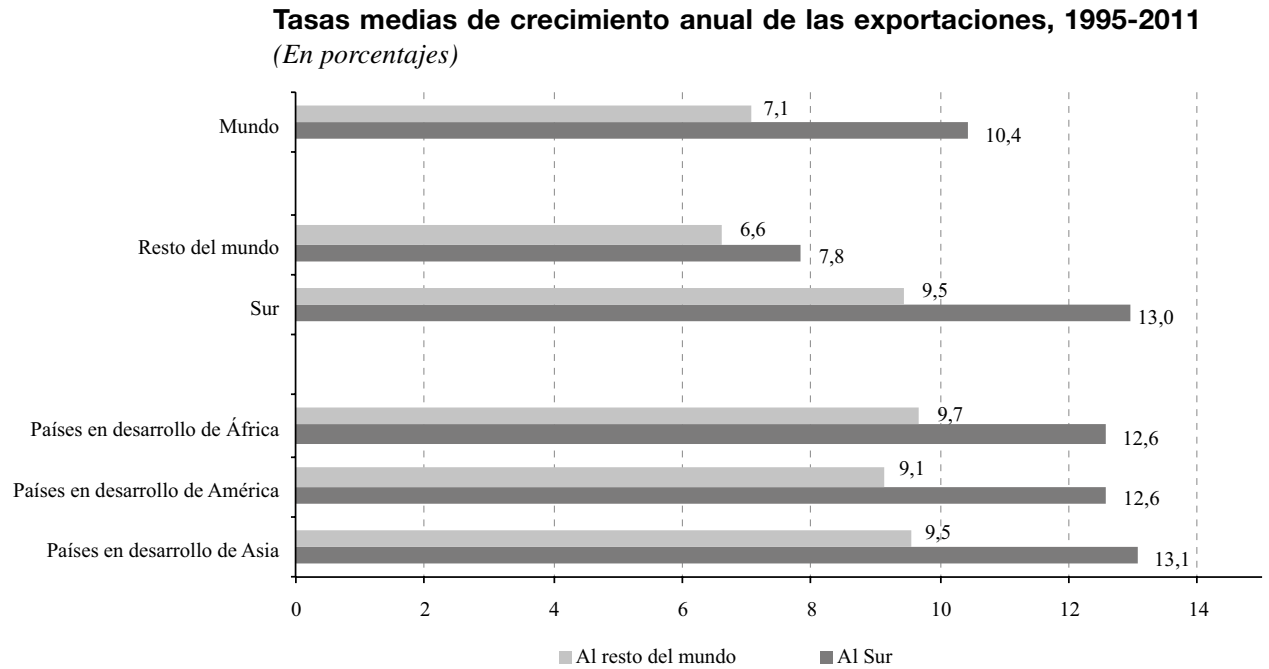

Fuente: Elaboración propia sobre la base de información de la base de datos UNCTADstat.

La rápida expansión del comercio Sur-Sur no puede entenderse si no se reconoce el papel cada vez más importante que juegan las redes mundiales y regionales de producción, algo que, a su vez, también explica la presencia predominante de Asia en el comercio Sur-Sur (y, de hecho, en el comercio mundial). Shaffaeddin (2008) considera que el acelerado crecimiento del comercio entre los países asiáticos ha sido, sobre todo, consecuencia de la industrialización y de la cooperación industrial en la región en forma de división de la producción. Athukorala (2011, pág. 12) señala que en Asia, la compleja división multinacional del trabajo en las redes de producción ha contribuido con creces a fortalecer la complementariedad comercial entre los países de la región, acelerando aún más el comercio intrarregional. En el análisis que se presenta a continuación se procurará reconocer estos distintos aspectos del comercio Sur-Sur al revisar los flujos del comercio interregional e intrarregional en Asia y América del Sur.

\section{III}

\section{¿Por qué el comercio Sur-Sur debería resultar beneficioso para los países en desarrollo?}

¿El comercio Sur-Sur es más provechoso que el comercio Sur-Norte para los países en desarrollo? ¿Por qué un cambio del esquema tradicional de comercio Sur-Norte a un mayor comercio Sur-Sur implicaría beneficios para los países de más bajos ingresos? En teoría, es posible encontrar al menos tres motivos.

En primer lugar, el comercio Sur-Sur puede suponer un mayor crecimiento del volumen de exportaciones. En gran parte de los últimos 30 años (y sobre todo en la década reciente), el crecimiento económico ha sido mucho más dinámico en los países más pobres del Sur Global, en especial en China y la India — las dos grandes “economías impulsoras de Asia” (Kaplinsky y Farooki, 2010, pág. 11) — que en los países ricos del Norte. El mejor desempeño de las economías en desarrollo y la brecha de crecimiento entre estas y las economías avanzadas convierten a las primeras en prometedores y atractivos mercados de exportación, en particular para los países en desarrollo con orientación al exterior. Fugazza y Vanzetti (2008) consideran que las potenciales ganancias derivadas de la eliminación de las barreras al comercio Sur-Sur serían considerablemente mayores que las que conlleva la apertura de los mercados del Norte (véanse también BASD, 2011; FMI, 2011; Wignaraja, Ramizo y Burmeister, 
2012). En realidad, ya se ha registrado una impresionante expansión del comercio Sur-Sur, especialmente en las últimas dos décadas, con una tasa de crecimiento más elevada que la del comercio mundial (Shirotori y Molina, 2009). Estos volúmenes más cuantiosos de exportaciones son posibles generadores de ingresos. No obstante, parte de este comercio Sur-Sur ha ocurrido solo en la literatura. La creciente integración de productores del Sur en redes de producción internacionales (a menudo llamadas "cadenas mundiales de valor") ha conducido a una fragmentación de los procesos de producción y a un nuevo patrón de comercio en el que los productos viajan por varios lugares antes de llegar al consumidor final. Por lo tanto, las estadísticas del comercio Sur-Sur incluyen un cierto grado de doble contabilización y deben interpretarse con precaución (BASD, 2011, pág. 50).

Una segunda forma en que el comercio Sur-Sur puede resultar provechoso para los países participantes es mediante el aumento del contenido tecnológico en los productos típicos de sus canastas exportadoras. En otras palabras, el comercio Sur-Sur puede beneficiar a los países en desarrollo si permite, o incluso promueve, la industrialización de alta tecnología en sus estructuras productivas. En particular, ello podría involucrar un cambio de la exportación de productos con baja intensidad en conocimientos especializados y poco valor agregado a productos con elevada o mayor intensidad en dichos conocimientos y alto o mayor valor agregado. Sin embargo, la evidencia respecto de esta hipótesis es variada. Shirotori y Molina (2009), por ejemplo, destacan que el sector dominante en el comercio Sur-Sur es el manufacturero, en tanto que Dahi y Demir (2008) señalan que la participación de las exportaciones de manufacturas en el total de exportaciones Sur-Sur se ha duplicado con creces en los últimos 30 años. A su vez, Klinger (2009) sostiene que para algunos países en desarrollo, sobre todo de África, América Latina y Asia Central, las exportaciones dirigidas al Sur son más sofisticadas y ofrecen más efectos de aprendizaje que las exportaciones destinadas al Norte. Esto viene a confirmar la observación de Dahi y Demir (2008) de que las exportaciones del Sur de manufacturas intensivas en tecnología y conocimientos especializados, dirigidas a mercados del Sur, han crecido más rápido que las exportaciones orientadas a mercados del Norte, de modo que en la actualidad el comercio Sur-Sur de manufacturas se caracteriza por una mayor intensidad de capital, tecnología y conocimientos especializados que el comercio Sur-Norte. Por su parte, la UNCTAD (2005) reveló que, en las últimas tres décadas, el sector más dinámico en términos del valor de las exportaciones en el comercio Sur-Norte fue el de la manufactura con mediana intensidad de conocimientos especializados, en tanto que en el comercio Sur-Sur, las manufacturas intensivas en trabajo y recursos registraron el crecimiento más dinámico. Además, Kaplinsky, Terheggen y Tijaja (2010) y Kaplinsky y Farooki (2010) predicen que el cambio de fuentes de demanda final del Norte al Sur (previsto como consecuencia de la reciente dinámica económica mundial y en especial de la reciente crisis) supondrá un cambio en la estructura y naturaleza de la demanda de importaciones. Los estándares de producción y productos perderán importancia en las cadenas mundiales de valor y los proveedores en los países en desarrollo se verán obligados a centrarse más en productos no procesados (con menos valor agregado y menos potencial para el aprendizaje y la actualización).

En tercer término, el comercio Sur-Sur podría resultar beneficioso para los países en desarrollo al mejorar la confiabilidad de la demanda para sus exportaciones, lo que sería de gran ayuda en su lucha por lograr la estabilidad macroeconómica. Una razón subyacente para ello podría ser la diversificación de las exportaciones. Es muy común que los países en desarrollo presenten una elevada concentración tanto en la canasta de productos de exportación, como en los mercados de exportación. La diversificación de las exportaciones reduciría esta concentración y disminuiría la dependencia de los países en desarrollo de uno o de unos pocos productos de exportación, destinos de exportación o de ambos. Otra explicación podría ser que los flujos del comercio Sur-Sur se caracterizan por una mayor elasticidad-ingreso de la demanda de importaciones que los flujos del comercio Sur-Norte. En esto se centra el resto del artículo. 
IV

\section{La elasticidad-ingreso de la demanda de importaciones: ¿es ventajoso el comercio Sur-Sur para el desarrollo de Asia y América del Sur?}

Básicamente, la elasticidad-ingreso de la demanda de un producto mide la respuesta de la cantidad demandada de ese producto a los cambios en el ingreso de los agentes económicos que lo consumen. Por lo tanto, en el contexto del comercio internacional, la elasticidad-ingreso de la demanda de importaciones indica la respuesta del flujo importaciones a los cambios en el ingreso del país importador. Cuanto mayor sea la elasticidad, mayor será el grado de respuesta de la demanda de importaciones cuando el ingreso del país importador aumente.

El principal objetivo de este artículo es realizar algunas estimaciones básicas de las elasticidades-ingreso de la demanda de importaciones del comercio Sur-Sur en comparación con el comercio Sur-Norte. La pregunta clave es: ¿cuál de estas elasticidades es mayor?

¿Por qué debería ocurrir esto? El razonamiento que subyace a una predicción de este tipo puede tener una dimensión vinculada tanto a la oferta como a la demanda. La dimensión de la oferta se relaciona con el segundo factor mencionado en la sección III: la composición de las canastas exportadoras de los países en desarrollo. Como ya se señaló, hay ciertos indicios de que en los flujos comerciales Sur-Sur se incluye una mayor participación de productos que habitualmente se espera se caractericen por una mayor elasticidad-ingreso de la demanda. Por ejemplo, suele decirse que los productos agrícolas o alimenticios tienen una elasticidad-ingreso de la demanda baja (o incluso negativa); es esperable que el ingreso extra, sobre todo en los niveles más altos, se invierta menos en alimentos. Por otra parte, en general se espera que la mayoría de los fabricantes tengan una elasticidad-ingreso de la demanda alta. Si la típica canasta de productos que un país en desarrollo importa de otros países en desarrollo contiene más manufacturas que productos primarios (o más productos con alta intensidad de conocimientos especializados que aquellos con baja intensidad de esos conocimientos) que la típica canasta de bienes que importa de una economía avanzada, puede esperarse que el comercio
Sur-Sur se caracterice por una mayor elasticidad-ingreso de la demanda de importaciones que el comercio Sur-Norte. Según ya se mencionó, el sector con más actividad comercial de todo el comercio Sur-Sur es el manufacturero, aunque no es necesariamente así en todos los países involucrados. Existe, de hecho, cierto grado de variación en las distintas regiones y si bien es verdad que, con una participación del $58 \%$, el manufacturero es el sector con más actividad comercial en el total del comercio Sur-Sur, este resultado se ve impulsado por el predominio de Asia, donde las manufacturas representan el $64 \%$ de todas las exportaciones Sur-Sur. En las otras regiones, esta cuota es muy inferior (un $35 \%$ en los países en desarrollo de América, un $28 \%$ en América del Sur y un $16 \%$ en África) ${ }^{5}$.

La dimensión de la demanda, por otra parte, hace referencia a la complementariedad del comercio y las estructuras productivas. Debido a diferencias en la etapa de desarrollo en general y la industrialización en particular, los países en desarrollo suelen diferir de las economías avanzadas en la estructura y naturaleza de la demanda (Kaplinsky y Farooki, 2010). La rápida industrialización en curso, en particular de las dinámicas economías asiáticas, conlleva una creciente demanda de materias primas, metales y energía. Por otra parte, la urbanización y los cambiantes modelos de preferencias y estilos de vida también suponen un aumento de la demanda de productos agrícolas y alimenticios importados, que puede ser bastante considerable teniendo en cuenta el enorme tamaño de las poblaciones de China y la India (UNCTAD, 2005, cap. 2). Todo ello sugiere que estos países del Sur en proceso de industrialización ofrecen prometedores mercados de exportación a otros países en desarrollo que se especializan en exportar productos primarios, en un

\footnotetext{
5 No obstante, también es interesante observar que esta cuota se ha reducido en todas las regiones desde el año 2000 (cuando en América del Sur, por ejemplo, llegaba al $42 \%$ ), muy probablemente como reflejo del auge del precio de los productos básicos.
} 
momento en que las estructuras productivas de los países industrializados del Norte cambian cada vez más de la industria a los servicios, lo que implica que en ellos se registre una merma en la demanda de materias primas e insumos industriales. Al mismo tiempo, la creciente integración de países en desarrollo en redes de producción regionales o mundiales supone que su demanda de productos intermedios y manufacturados también va en aumento. Athukorala (2011) sostiene que la mayor integración del Sur en cadenas mundiales y regionales de valor ha contribuido no solo a la diversificación de sus estructuras productivas, sino también a la creciente complementariedad comercial entre las economías de este bloque. Sin embargo, hasta el momento la demanda de los productos finales elaborados en esas cadenas mundiales de valor ha provenido sobre todo de países del Norte. Esto podría cambiar como consecuencia de las trascendentales repercusiones de la reciente crisis económica mundial.

Un cambio de mercados de exportación del Norte al Sur tendrá importantes consecuencias en la estructura y naturaleza de la demanda. Mientras que las preferencias de los consumidores del Norte se basan cada vez más en la calidad, la innovación y la diferenciación de los productos, en los países en desarrollo el principal determinante de la demanda suele ser simplemente el precio de un producto (Kaplinsky y Farooki, 2010). Además, la estructura de la demanda es distinta no solo para los bienes de consumo, sino también para los bienes de capital. De hecho, el comercio Sur-Sur ofrece a los países en desarrollo acceso a bienes de capital asequibles, que suelen adecuarse mejor a sus necesidades que los provenientes de países más ricos, por lo que tienen más posibilidades de ser adquiridos, adoptados e imitados (PNUD, 2013, pág. 58). La expectativa generalizada de que, al menos de corto a mediano plazo, el crecimiento económico sea mucho más dinámico en el Sur que en el
Norte, supone que habrá una mayor demanda de este tipo de productos. Debido a que estos bienes en general se producen en países en desarrollo en el Sur, la demanda de importaciones complementa la oferta de exportaciones, lo que da un mayor impulso al comercio Sur-Sur. Esto lo confirman Shirotori y Molina (2009), quienes sostienen que la especialización sectorial en el comercio Sur-Sur y, por tanto, la complementariedad comercial están aumentando. De modo similar, aunque centrándose más en el comercio entre los países de bajos ingresos y los países BRIC (Brasil, Federación de Rusia, India y China), en un artículo del Fondo Monetario Internacional (FMI) se da cuenta de las fuertes complementariedades económicas entre ambos grupos de países en virtud de las complementariedades en materia de dotaciones de recursos y estructuras productivas. Mediante el uso de un índice de complementariedad comercial, en este artículo se muestra que la complementariedad de las exportaciones suele ser mayor entre países de bajos ingresos y China o la India, que entre países de bajos ingresos y los Estados Unidos de América o la Unión Europea (FMI, 2011, pág. 14).

En suma, la hipótesis de que el comercio Sur-Sur se caracteriza por mayores elasticidades-ingreso de la demanda de importaciones que el comercio SurNorte puede derivar del supuesto de que el primero se basa en distintas carteras de exportaciones (con más elevada participación de manufacturas y productos más sofisticados) y presenta una mayor complementariedad comercial (la demanda de importaciones satisface la oferta de exportaciones). Resulta evidente que una mayor elasticidad-ingreso de la demanda de importaciones del Sur hará que la expansión del comercio Sur-Sur resulte particularmente beneficiosa para los países en desarrollo, si continúa siendo verdad la primera condición mencionada anteriormente: la existencia de una brecha de crecimiento entre el Sur y el Norte.

\section{V}

\section{Modelo y enfoque empírico}

En lo que respecta al modelo econométrico a estimar, en este trabajo se utiliza una función de demanda de importaciones estándar basada en el modelo de sustitución imperfecta que describen Goldstein y Khan (1985), donde se asume que los productos extranjeros y nacionales son sustitutos imperfectos. Esto puede escribirse de la siguiente manera:

$$
\ln M_{t}^{j}=\alpha+\beta \ln Y_{t}+\gamma \ln E_{t}^{j}+\varepsilon_{t}
$$


donde $\ln$ representa la función logaritmo natural, $M$ es la demanda de importaciones del país $j, Y$ es el ingreso nacional real, $E$ es el tipo de cambio bilateral real entre el país de origen y el país $j$ en el momento $t$ (definido como la cantidad de unidades de moneda local por unidad de moneda extranjera ajustada por niveles de precios nacional y extranjero), y $\varepsilon_{t}$ es el término de error aleatorio ${ }^{6}$. La hipótesis es que un mayor ingreso se relaciona con una mayor demanda de importaciones, o sea que ese parámetro $\beta$ es positivo. Se espera que el parámetro $\gamma$ sea negativo, lo que supone que una apreciación real de la moneda nacional se asocia con una mayor demanda de importaciones.

A continuación se adopta la estrategia adoptada por Milberg y Winkler (2010), Bahmani-Oskooee y Kara (2005) y Bahmani-Oskooee, Goswamil y Talukdar (2005). Estos autores estiman elasticidades-ingreso de la demanda de importaciones a largo plazo para los Estados Unidos de América, el Canadá y otros países, respectivamente, usando un modelo de retardo distribuido autorregresivo (ARDL) para la cointegración que, según Pesaran, Shin y Smith (2001), produce estimaciones constantes de los coeficientes a largo plazo, sin importar si los regresores son estacionarios o no (es decir, si son integrados de orden 0 o 1 , o superior: $\mathrm{I}(0)$ o $\mathrm{I}(1)^{7}$. Esta estrategia es conveniente, entonces, porque no requiere la realización de una prueba previa de raíz unitaria y posee propiedades de muestra pequeña deseables (véanse, por ejemplo, Pesaran y Shin, 1999, o Panopoulou y Pittis, 2004), lo que es importante para el presente trabajo ${ }^{8}$. La estrategia

6 Aquí cabe hacer dos advertencias. En primer término, en este modelo se combinan datos en volúmenes (PIB) con datos en valores (importaciones) y ello puede sesgar las estimaciones de elasticidadesingreso. En segundo lugar, como las importaciones se miden en términos de valor, los aumentos pueden estar impulsados por incrementos en los precios de los productos. Esto tiene especial importancia para las exportaciones de América del Sur, cuyo crecimiento entre 2004 y 2011 se debió, en gran parte, al aumento de los precios de los productos básicos. En consecuencia, las futuras estimaciones econométricas también deberían tratar de captar esas fluctuaciones de precios.

$7 \mathrm{El}$ problema es que es esperable que la mayoría de las variables incluidas en la función de demanda de importaciones tengan series cronológicas no estacionarias (o sea, que sean integrados de orden 1 o superior) las que, cuando se utilizan en una regresión de cuadrados ordinarios (MCO) estándar, pueden dar resultados confusos e inferencias erróneas en lo que se conoce como el problema de "regresión espuria". Para evitar este problema, en la literatura econométrica se han ideado diversas técnicas de estimación de cointegración y aquí se aplica una de ellas: el marco ARDL.

8 Dadas las propiedades deseables detalladas anteriormente, el marco ARDL se ha utilizado en varios artículos recientes donde se investigan y estiman las elasticidades del comercio, incluidos los de Bahmani-Oskooee y Kara (2005), Bahmani-Oskooee, Goswamil y del ARDL incluye variables de nivel retardadas y agrega una dinámica de corto plazo (mediante la inclusión de variables diferenciadas retardadas y contemporáneas) a una ecuación de estimación de largo plazo como la presentada anteriormente, dando como resultado:

$$
\begin{gathered}
\Delta M_{t}^{j}=\alpha+\sum_{i=1}^{n} \beta_{i} \Delta \ln Y_{t-i}+\sum_{i=1}^{n} \gamma_{i} \Delta \ln E_{t-i}^{j} \\
+\sum_{i=1}^{n} \delta_{i} \Delta \ln E_{t-i}^{j}+v_{1} \ln Y_{t-1}+v_{2} \ln E_{t-1}^{j} \\
+v_{3} \ln M_{t-1}^{j}+\epsilon_{t}
\end{gathered}
$$

En la ecuación (2), las variables de nivel retardadas para $Y, E$ y $M$ constituyen el término de corrección de error (retardado). Dependiendo del estadístico F, este término de corrección de error retardado debe ser retenido o excluido de la ecuación; Pesaran, Shin y Smith (2001) proporcionan límites de valor crítico. Si el estadístico $\mathrm{F}$ es mayor que el límite superior de valor crítico informado por estos autores, la hipótesis nula de $v 1=v 2=v 3=0$ es rechazada, o sea que las variables de nivel retardadas son cointegradas y se mantienen en la ecuación (2) ${ }^{9}$.

Talukdar (2005), y Milberg y Winkler (2010), así como Chang, Ho y Huang (2005) para la República de Corea; Uz (2010) para Turquía; Yin y Hamori (2011) para China, y Grullón (2012) para la República Dominicana. En la literatura empírica previa donde se estimaban las elasticidades-ingreso de la demanda de importaciones también se aplicaban otros métodos econométricos, aunque no en todos se usaban técnicas de cointegración. Kwack y otros (2005), por ejemplo, realizaron una simple estimación de panel de MCo para varios países. Thorbecke y Komoto (2010) presentan estimaciones de elasticidades globales del comercio para los Estados Unidos de América y diversos países asiáticos usando el estimador de mínimos cuadrados ordinarios dinámicos (DOLS, por sus siglas en inglés) creado por Stock y Watson (1993), que añade retardos y adelantos de los regresores. Uz (2010) recurre a cinco métodos distintos para estimar las relaciones comerciales (de cointegración) de largo plazo para Turquía, incluidos los DOLS y el ARDL. Yin y Hamori (2011) estiman las elasticidades-ingreso a largo plazo para China usando no solo el modelo ARDL, sino también la técnica de DOLS. En este trabajo, no obstante, no se recurre a la estrategia de los DOLS, ya que agregar retardos y adelantos para las variables explicativas requiere la disponibilidad de series de largo plazo para las variables en el modelo, algo que no es fácil de encontrar en los países en desarrollo, incluidos aquellos en los que se centrará el análisis de este artículo, donde la disponibilidad de los datos es un problema y las series cronológicas no datan de mucho tiempo atrás.

${ }^{9}$ Véase información sobre fuentes de datos en el anexo A y más detalles sobre el procedimiento de estimación en el anexo B. 


\section{VI}

\section{Objetivo del análisis y resultados de la regresión}

En este trabajo el análisis se centrará en un segmento intercontinental (o interregional) específico del comercio Sur-Sur, concretamente en el comercio entre los países de Asia y América del Sur, así como en el comercio intracontinental de ambas regiones. El motivo de esta elección es que promete ser un ejemplo particularmente interesante, dado que el alcance para la explotación del comercio interregional es especialmente evidente entre Asia y América (Shirotori y Molina, 2009, pág. 11). La complementariedad comercial entre Asia, Centroamérica y América del Sur parece ser particularmente fuerte (UNCTAD, 2008, pág. 14). Al observar la lista de sectores con mayor actividad comercial entre ambas regiones, se obtiene cierto grado de confirmación con respecto a esta idea. Mientras que la mayoría de las exportaciones de Asia a América consisten en productos del sector manufacturero, las exportaciones de América del Sur a Asia se componen principalmente de productos agrícolas y productos obtenidos de la explotación de recursos naturales. Además de analizar el comercio interregional entre Asia y América del Sur, también interesa comparar las elasticidades-ingreso de la demanda de importaciones en el comercio interregional en comparación con el comercio intrarregional. De conformidad con la literatura del modelo gravitacional, donde se destaca la relevancia de factores como la proximidad geográfica, las fronteras compartidas, el idioma común y la familiaridad cultural como impulsores del comercio (véase, por ejemplo, Kwack y otros, 2005), al parecer las elasticidades son mayores en el comercio intrarregional que en el interregional. Esto se verifica al analizar las elasticidades en el comercio dentro de Asia y de América del Sur.

Como ya se señaló, el comercio intrarregional es muy importante para las economías en desarrollo de Asia. De hecho, el 51,8\% de todas las exportaciones provenientes de los países en desarrollo de Asia se dirigen a otros países asiáticos (en 1995 esta cifra ascendía al 42,2\%). En América del Sur, en cambio, el comercio intrarregional no tiene tanta relevancia. Si bien las exportaciones intrarregionales han registrado un rápido crecimiento y se han cuadruplicado en los últimos 15 años, no han estado a la altura de las exportaciones totales de América del Sur al mundo (que se quintuplicaron en el mismo período), de modo que la participación de las exportaciones intrarregionales en el total de exportaciones se redujo del $24,7 \%$ en 1995 al 19,3\% en 2011.

El análisis efectuado se concentrará en los agentes clave de ambas regiones: China, la India, Indonesia y la República de Corea, como representantes de los países en desarrollo de Asia, y la Argentina, el Brasil, Chile y el Perú como representantes de América del Sur. Como último paso, se analizará cómo las elasticidades-ingreso en el comercio Sur-Sur se comparan con las del comercio Sur-Norte, representadas por el comercio entre estos países y los Estados Unidos de América y la zona del euro (los países de la Unión Europea que adoptaron el euro como moneda común).

\section{El comercio Sur-Sur}

El primer conjunto de regresiones tiene por objeto estimar las elasticidades-ingreso que caracterizan a las distintas relaciones comerciales bilaterales, tanto en el comercio Sur-Sur interregional (entre países de América del Sur, por una parte, y países de Asia, por la otra) como en el comercio Sur-Sur intrarregional (dentro de América del Sur y Asia, respectivamente). Los coeficientes estimados para las elasticidades-ingreso de la demanda de importaciones para todas las relaciones comerciales bilaterales pueden encontrarse en la parte superior del cuadro 1.

\section{a) Elasticidades-ingreso de la demanda de importaciones de América del Sur}

En primer término, en este estudio se procederá a analizar los flujos comerciales bilaterales hacia los países de América del Sur, ya sean provenientes de Asia o de otros países sudamericanos. Como ya se expresó, interesan sobre todo las elasticidades-ingreso de la demanda de importaciones de América del Sur para productos y servicios provenientes de socios comerciales de Asia o sudamericanos. Los resultados de la estimación para los correspondientes coeficientes proporcionados por los modelos de regresión finales se muestran en las filas 1 a 4 del cuadro $1^{10}$.

\footnotetext{
${ }^{10}$ En un anexo adicional (denominado anexo C), no incluido en este artículo por motivos de extensión, se presentan resultados más detallados de la estimación. Esta información puede ser solicitada al autor.
} 


\begin{tabular}{|c|c|c|c|c|c|c|c|c|}
\hline \multirow{2}{*}{ Importador } & \multicolumn{8}{|c|}{ Socio comercial } \\
\hline & Argentina & Brasil & Chile & Perú & China & India & Indonesia & República de Corea \\
\hline Brasil & $0,629 * * *$ & $\ldots$ & $0,424 * * *$ & $0,407 * * *$ & $0,560 * * *$ & $0,890 * * *$ & $0,599 * * *$ & $0,427 * * *$ \\
\hline Chile & 0,490 & $0,715 * * *$ & $\ldots$ & $0,247 * *$ & $1,543 * * *$ & $0,811 * * *$ & $0,591 * * *$ & $0,628 * * *$ \\
\hline Perú & $0,517 * * *$ & $0,386 * * *$ & $0,528 * * *$ & $\ldots$ & $0,526 * * *$ & $1,502 * * *$ & $0,494 * * *$ & $0,529 * * *$ \\
\hline India & $0,254 * * *$ & $1,564 * * *$ & $1,316^{* * *}$ & $1,797 * * *$ & $\begin{array}{r}0,676^{a} \\
(0,232)\end{array}$ & $\begin{array}{c}(0,705 * * *) \\
\ldots\end{array}$ & $0,402 * * *$ & $\begin{array}{c}(0,239 * * *) \\
1,549^{\mathrm{a}} \\
(0,737 * *)\end{array}$ \\
\hline Indonesia & $0,761 * * *$ & $0,999 * * *$ & $1,165 * *$ & $0,285 * * *$ & $0,841 * * *$ & $2,020 * * *$ & $\ldots$ & $0,344 * * *$ \\
\hline República de Corea & $0,751 * * *$ & $0,649 * * *$ & $0,656^{* * *}$ & $1,118^{* * *}$ & $0,674 * * *$ & $1,214 * * *$ & $0,500^{* * *}$ & $\ldots$ \\
\hline Zona del euro & $0,261 * *$ & $1,126 * * *$ & 0,124 & $0,532 *$ & $0,685 * * *$ & $0,295 * * *$ & $0,462 * * *$ & $1,192 * * *$ \\
\hline Estados Unidos de América & $1,128 * * *$ & $0,913 * * *$ & $1,740 * * *$ & $1,609 * * *$ & $2,606 * * *$ & 0,244 & $0,288 * *$ & 0,0218 \\
\hline
\end{tabular}

Fuente: Elaboración propia.

a La elasticidad-ingreso de la demanda de importaciones a corto plazo, calculada como la suma de todos los coeficientes de corto plazo estadísticamente significativos, es decir, $\sum_{i=1}^{n} \beta_{i}$ (véanse Debelle y Vickery (1998) y Chatelain y Tiomo (2001)). De acuerdo con Milberg y Winkler (2010, pág. 66), también se registra (entre paréntesis) el coeficiente estimado para la primera variable de ingreso diferenciada. * significativo al $10 \%$; ** significativo al $5 \%$; *** significativo al $1 \%$.

También en el cuadro 1 se evidencia que las elasticidades-ingreso de la demanda de importaciones en los flujos comerciales interregionales de Asia hacia América del Sur van de un mínimo de 0,19 (en el caso de las importaciones de productos y servicios de la India a la Argentina) a un máximo de 1,54 (para las importaciones chilenas provenientes de China). Más precisamente, las elasticidades-ingreso de las importaciones de la Argentina provenientes de China, la India, Indonesia y la República de Corea son de 0,22, 0,19, 0,26 y 0,55, respectivamente, lo que indica que un incremento de $1 \%$ en el ingreso de la Argentina aumentará 0,22\% las importaciones provenientes de China, $0,19 \%$ las de la India, $0,26 \%$ las de Indonesia y 0,55\% las de la República de Corea. A su vez, un incremento de $1 \%$ en el ingreso del Brasil supondrá un aumento de $0,56 \%$ de las importaciones brasileñas de China, de $0,89 \%$ de sus importaciones de la India, de $0,60 \%$ de las de Indonesia y un alza del 0,43\% de las importaciones brasileñas de la República de Corea. En tanto, las elasticidades-ingreso en el caso de Chile son bastante altas, de 1,54, 0,81, 0,59 y 0,63 respecto de sus importaciones de China, la India, Indonesia y la República de Corea, respectivamente. Por último, si el producto interno bruto (PIB) del Perú crece un 1\%, el mayor impacto se sentirá en las importaciones del país desde la India $(1,50 \%)$ y el menor efecto se registrará en sus importaciones desde Indonesia (0,49\%). En promedio, un incremento de $1 \%$ en el ingreso de los cuatro países sudamericanos provoca un aumento de $0,644 \%$ en las importaciones bilaterales provenientes de las cuatro economías asiáticas: los flujos comerciales bilaterales de Asia a América del Sur se caracterizan por una elasticidad-ingreso de la demanda de importaciones media simple (no ponderada) en torno del $0,6 \%$.

$\mathrm{Al}$ analizar el comercio intrarregional, en el cuadro 1 se observa que las elasticidades-ingreso de la demanda de importaciones en los flujos comerciales dentro de América del Sur varían de un mínimo de 0,17 (en el caso de las importaciones de la Argentina provenientes del Brasil) a un máximo de 0,72 (para las importaciones chilenas desde el Brasil). Las elasticidades del comercio son particularmente bajas en el caso de las importaciones de la Argentina provenientes de sus socios comerciales de América del Sur y solo un poco más altas cuando se trata de las importaciones brasileñas, chilenas y peruanas. El promedio simple no ponderado de las elasticidadesingreso de la demanda de importaciones en el comercio intrarregional Sur-Sur entre países de América del Sur es de tan solo 0,555 (véase el cuadro 2). En general, el comercio intrarregional en América del Sur se caracteriza, en consecuencia, por elasticidades-ingreso más bajas que las importaciones extrarregionales de esta subregión provenientes de Asia (que llegan a un promedio de 0,644), lo que contradice la hipótesis de este trabajo. 


\begin{tabular}{|c|c|c|}
\hline \multirow{3}{*}{ Importador } & \multicolumn{2}{|c|}{ Comercio Sur-Sur } \\
\hline & \multicolumn{2}{|c|}{ Socio comercial } \\
\hline & Asia & América del Sur \\
\hline Asia & 0,940 & 0,854 \\
\hline \multirow[t]{2}{*}{ América del Sur } & 0,644 & 0,555 \\
\hline & \multicolumn{2}{|c|}{ Comercio Sur-Norte } \\
\hline \multirow[t]{2}{*}{ Importador } & \multicolumn{2}{|c|}{ Socio comercial } \\
\hline & Asia & América del Sur \\
\hline Zona del euro & 0,658 & 0,511 \\
\hline Estados Unidos de América & 0,790 & 1,347 \\
\hline
\end{tabular}

Fuente: Elaboración propia.

\section{b) Elasticidades-ingreso de la demanda de importaciones de Asia}

La segunda parte de este estudio del comercio SurSur consiste en analizar los flujos comerciales bilaterales que llegan a Asia. En las filas 5 a 8 del cuadro 1 se incluyen los coeficientes estimados que representan las elasticidades-ingreso de la demanda de importaciones por parte de Asia para productos y servicios tanto de América del Sur como de otros socios comerciales asiáticos.

Como puede observarse, las elasticidades-ingreso de la demanda de importaciones en los flujos comerciales interregionales de América del Sur al Asia van de un mínimo de 0,25 (en el caso de las importaciones de la India de productos argentinos) a un máximo de 1,80 (para las importaciones de la India provenientes del Perú). En general, las elasticidades-ingreso de la demanda de importaciones de América del Sur, en promedio, parecen ser mayores en la India entre los países asiáticos de la muestra. Con mayor precisión, las elasticidades-ingreso estimadas de las importaciones de la India provenientes de la Argentina, el Brasil, Chile y el Perú ascienden a $0,25,1,56,1,32$ y 1,80 , respectivamente. En tanto, se estima que un aumento de $1 \%$ en el ingreso de China generaría incrementos de $0,38 \%, 0,90 \%, 0,61 \%$ y $0,47 \%$ en sus importaciones desde la Argentina, el Brasil, Chile y el Perú, respectivamente. En el caso de Indonesia, un aumento de $1 \%$ del PIB incrementará más sus importaciones desde Chile $(1,17 \%)$ y menos las del Perú $(0,29 \%)$. Por último, si el ingreso de la República de Corea aumenta un $1 \%$, sus importaciones provenientes del Perú se incrementarán un $1,12 \%$, pero las que provienen del Brasil solo aumentarán un $0,65 \%$. En promedio, un incremento de $1 \%$ en el ingreso de los cuatro países asiáticos de la muestra de este artículo genera un aumento de $0,854 \%$ en sus importaciones bilaterales provenientes de las cuatro economías sudamericanas: los flujos comerciales interregionales de América del Sur a Asia se caracterizan por una elasticidad-ingreso de la demanda bilateral de importaciones media en torno del $0,9 \%$.

Antes de revisar el comercio intrarregional en Asia, es necesario advertir que no todos los valores del cuadro 1 son estrictamente comparables. En cuatro casos (las importaciones de China provenientes de la India y la República de Corea y las importaciones de la India que provienen de China y la República de Corea), los ejercicios econométricos presentaron problemas de especificación que hicieron que se abandonara el término de corrección de error incluido en el modelo original ${ }^{11}$. Para estos cuatro casos, en el cuadro 1 se incluyen únicamente los efectos a corto plazo de los cambios en el ingreso sobre la demanda de importaciones (los efectos de $\ln Y_{t-1}$, mientras que todos los demás datos representan elasticidades-ingreso de la demanda de importaciones

\footnotetext{
${ }^{11}$ En estos cuatro casos, como se muestra en los cuadros C.5 y C.6 del anexo C, el estadístico F superó el límite superior de valor crítico en el nivel de significación del 10\%, como lo especifican Pesaran, Shin y Smith (2001), lo que indica que el término de corrección de error retardado debe excluirse de la ecuación. No obstante, como el coeficiente para la variable de nivel retardada para Y (que forma parte del término de corrección de error) es el que da el "equilibrio" a largo plazo en la elasticidad-ingreso de la demanda de importaciones, solo se puede informar sobre las elasticidades-ingreso a corto plazo para estas cuatro relaciones comerciales bilaterales. Véase más información en las explicaciones incluidas en el anexo $\mathrm{C}$.
} 
a largo plazo. De hecho, en el cuadro 1 se registran dos cifras para estos cuatro casos. Primero se indica la suma de todos los coeficientes de corto plazo estadísticamente significativos, esto es, $\sum_{i=1}^{n} \beta_{i}$, como una aproximación a los efectos del ingreso a largo plazo (de conformidad con lo explicado, por ejemplo, por Debelle y Vickery (1998) y Chatelain y Tiomo (2001)). A continuación se presenta (entre paréntesis) el coeficiente estimado para las primeras variables de ingreso diferenciadas $\left(\beta_{1}\right)$, siguiendo la estrategia adoptada por Milberg y Winkler (2010, pág. 66).

Según se puede observar en el cuadro 1, las elasticidades-ingreso de la demanda de importaciones en los flujos comerciales intrarregionales de Asia van de un mínimo de 0,34 (en el caso de las importaciones de Indonesia provenientes de la República de Corea) a un máximo de 2,02 (para las importaciones de Indonesia provenientes de la India). En general, Indonesia registra las elasticidades comerciales más altas para sus importaciones intrarregionales, seguida de China. Un aumento de $1 \%$ en el ingreso chino conduce a una expansión estimada de 1,58\% en sus importaciones provenientes de la India, a un incremento de $0,94 \%$ en las importaciones desde Indonesia y a un alza de $0,50 \%$ en las importaciones desde la República de Corea. En tanto, las elasticidades-ingreso también son comparativamente elevadas en el comercio entre la India y la República de Corea: un aumento de $1 \%$ en el ingreso de la India se estima que acrecienta un $1,55 \%$ sus importaciones provenientes de la República de Corea, mientras que si el PIB real de la República de Corea se incrementa un $1 \%$, sus importaciones desde la India crecerán un 1,21\%. En términos generales, el comercio intrarregional entre las economías asiáticas es, en consecuencia, bastante elástico en relación con el ingreso. El promedio simple de las elasticidades-ingreso de la demanda de importaciones en el comercio intrarregional Sur-Sur en Asia se calcula que asciende a 0,94. Este valor no solo supera, como era de esperar, las elasticidades medias para las importaciones extrarregionales de Asia provenientes de América del Sur $(0,85)$, sino que también es mayor que el promedio de las elasticidades-ingreso en el comercio intrarregional en América del Sur $(0,64)$ (véase el cuadro 2). Podría decirse que este último hecho refleja la integración económica más avanzada y la división de la producción más refinada entre los países asiáticos.

\section{El comercio Sur-Norte}

Como lo que en realidad interesa es comparar la promesa que encierra el comercio Sur-Sur con relación al comercio Sur-Norte, se procurará obtener una idea de las elasticidades-ingreso de la demanda de importaciones en el comercio Sur-Norte. Por lo tanto, en el segundo conjunto de regresiones de este trabajo se estimarán las elasticidades-ingreso que caracterizan a las distintas relaciones comerciales bilaterales entre la zona del euro y los Estados Unidos de América, por una parte, y los países de Asia y América del Sur, por otra.

\section{a) Importaciones de la zona del euro provenientes} de Asia y de América del Sur

En el primer paso del análisis del comercio SurNorte, se analizarán los flujos comerciales desde Asia y América del Sur hacia la zona del euro. Los resultados de la estimación para las elasticidades-ingreso de la demanda de importaciones de la zona del euro para productos y servicios de Asia y América del Sur se presentan en la fila 9 del cuadro 1. Allí puede apreciarse que las elasticidades-ingreso son mayores para la demanda de importaciones de la zona del euro provenientes de la República de Corea $(1,19)$ y el Brasil $(1,13)$, y menores para las importaciones provenientes de Chile $(0,12)$ y la Argentina $(0,26)$, además de ser también más bien bajas para las importaciones provenientes del Perú $(0,53)$, el cuarto país sudamericano de la muestra aquí incluida. En tanto, como puede observarse en el cuadro 1 , un aumento de $1 \%$ en el ingreso de la zona del euro generará una expansión de $0,69 \%$ en las importaciones de la zona del euro provenientes de China, un incremento de $0,30 \%$ de aquellas que provienen de la India y un alza de $0,46 \%$ en las importaciones desde Indonesia. En general, las elasticidades-ingreso son, por lo tanto, mayores en el caso de la demanda de importaciones de la zona del euro provenientes de Asia (0,66 en promedio) que de América del Sur (0,51 en promedio) (véase el cuadro 2).

\section{b) Importaciones de los Estados Unidos de América} provenientes de Asia y de América del Sur

Para tener un panorama más completo del comercio Sur-Norte, el último paso del presente análisis consiste en estimar las elasticidades-ingreso de la demanda de importaciones de los Estados Unidos de América para productos y servicios de Asia y América del Sur. Los resultados de las correspondientes regresiones se presentan en la fila 10 del cuadro 1 , donde se denota que las elasticidades-ingreso de la demanda de importaciones en los flujos comerciales provenientes del Sur y dirigidos a los Estados Unidos de América son mayores para China $(2,61)$ y más bien bajas para los otros países asiáticos considerados: 0,29 para Indonesia, 0,24 para la India y tan solo 0,02 para la República de Corea. Por otra parte, las importaciones estadounidenses provenientes de 
países de América del Sur en la muestra se caracterizan por elasticidades-ingreso más bien altas. Con mayor precisión, las elasticidades-ingreso para las importaciones estadounidenses provenientes de la Argentina, el Brasil, Chile y el Perú ascienden a 1,13, 0,91, 1,74 y 1,61, respectivamente. En promedio, una expansión del $1 \%$ en el ingreso de los Estados Unidos de América aumentará un 1,35\% las importaciones estadounidenses provenientes de las cuatro economías sudamericanas y solo un $0,79 \%$ las que provienen de los cuatro países asiáticos de la muestra. En otras palabras, y al contrario de los resultados obtenidos para las importaciones de la zona del euro, las elasticidades-ingreso medias son superiores para la demanda de importaciones de los Estados Unidos de América provenientes de América del Sur que de Asia (véase el cuadro 2).

Al comparar los dos mercados del Norte que aquí se analizan, puede observarse que, en general, la demanda de importaciones de los Estados Unidos de América se caracteriza por mayores elasticidades-ingreso que la demanda de importaciones de la zona del euro. Si bien esto no es así respecto de todas las relaciones comerciales bilaterales, los promedios simples no ponderados registrados en la parte inferior del cuadro 2 permiten ver que las elasticidades-ingreso medias de los Estados Unidos de América superan a las de la zona del euro en cuanto a la demanda de importaciones provenientes tanto de Asia $(0,79$ comparado con 0,66$)$ como de América del Sur (1,35 comparado con 0,51). Al comparar los flujos comerciales Sur-Norte en las regiones de origen, sorprende descubrir que las elasticidades-ingreso medias de la demanda de importaciones del Norte procedentes de América del Sur superan a las elasticidades en los flujos comerciales dirigidos al Norte Global, originados en los países en desarrollo de Asia (0,93 comparado con 0,72$)$.

Antes de realizar la comparación y discusión de las elasticidades-ingreso del comercio Sur-Sur en relación con el comercio Sur-Norte en la sección VII, se hará un breve cotejo de los resultados obtenidos aquí con los de otros estudios empíricos. Sin embargo, al efectuar estas comparaciones entre estudios es importante recordar la existencia de ciertas diferencias en los enfoques, las metodologías y los datos usados, que pueden explicar gran parte de las disparidades de los resultados obtenidos. Sin embargo, en general la magnitud de las elasticidades-ingreso de la demanda de importaciones aquí estimadas coincide con los resultados obtenidos por Bahmani-Oskooee y Kara (2005), que dan cuenta de una elasticidad-ingreso de largo plazo estimada que va de 0,14 para el Japón a 2,10 para los Estados Unidos de América. Las estimaciones del presente trabajo también son consistentes con las de Milberg y Winkler (2010), que registran elasticidades-ingreso de la demanda de importaciones (estadísticamente significativas) de largo plazo de 0,77 para la provincia china de Taiwán, de 1,24 para el Brasil y de 1,86 para Alemania, al tiempo que sus estimaciones para China y la India sobrepasan con creces las de este trabajo.

Grullón (2012), Yin y Hamori (2011), y Chang, Ho y Huang (2005) informan estimaciones de elasticidadesingreso de largo plazo que, en promedio, son levemente superiores a las de esta investigación y van de 1,37 para la República Dominicana a 1,86 para la República de Corea y 2,66 para China. Lo mismo ocurre en el caso de Thorbecke y Komoto (2010), quienes estiman que las elasticidades-ingreso de la demanda de importaciones de largo plazo de varios países van de 1,32 para la República de Corea y 1,45 para la provincia china de Taiwán a 2,14 para los Estados Unidos de América. De modo similar, a partir de las regresiones realizadas por Kwack y otros (2005) se obtienen coeficientes que son algo superiores a los de este trabajo y van de un mínimo de 1,05 para Singapur a un máximo de 3,28 para las Filipinas. Es importante destacar que los resultados de todos estos estudios no son totalmente comparables con los aquí efectuados, ya que para cada país de su muestra estiman elasticidades-ingreso de la demanda de importaciones "globales" provenientes de todos los socios comerciales del país en cuestión, mientras que aquí se estiman elasticidades-ingreso bilaterales. Además, en los últimos dos estudios mencionados se usan datos anuales (en oposición a los datos trimestrales utilizados en este trabajo) y su variable dependiente son las importaciones reales en niveles, no en primeras diferencias como en el caso presente.

En los trabajos de Bahmani-Oskooee, Goswamil y Talukdar (2005), y Uz (2010) se investigan las elasticidades-ingreso en las relaciones comerciales bilaterales utilizando datos trimestrales y el modelo ARDL. En ambos estudios se producen estimaciones que, en general, son superiores a las de esta investigación. Empero, estos análisis se refieren al Canadá y Turquía, dos países que no están incluidos en la presente muestra. Si bien es difícil descubrir qué es lo que explica las diferencias entre los resultados de esos estudios y los que aquí se exponen, hay que señalar que BahmaniOskooee, Goswamil y Talukdar (2005) utilizan el marco ARDL, pero mantienen el término de corrección de error (incluidas las variables de nivel retardadas), sin importar el estadístico F, de modo que no todos los coeficientes que se incluyen en dichos trabajos son estadísticamente significativos. 


\section{VII}

\section{Pasado y futuro: una comparación entre el comercio Sur-Sur y el comercio Sur-Norte}

En la sección VI se presentaron los resultados del análisis econométrico de las elasticidades-ingreso en el comercio Sur-Sur y el comercio Sur-Norte. Estos ofrecen una variedad de pruebas con respecto a la hipótesis de que el comercio Sur-Sur suele caracterizarse por mayores elasticidades-ingreso de la demanda de importaciones que el comercio Sur-Norte. Por otra parte, la actividad económica en los Estados Unidos de América, uno de los mercados clave del Norte, se caracteriza por elasticidades-ingreso comparativamente altas para las importaciones provenientes del Sur Global $y$, por lo tanto, este representa un atractivo destino de exportación. En efecto, las elasticidades-ingreso de la demanda de importaciones provenientes de América del Sur (representada por la Argentina, el Brasil, Chile y el Perú) son más altas en los Estados Unidos de América, esto es, más elevadas que en el comercio intrarregional Sur-Sur (dentro de América del Sur), en el comercio interregional Sur-Sur (de América del Sur a Asia) y en el comercio Sur-Norte (de América del Sur a la zona del euro) (véase el cuadro 2). En lo que respecta a importaciones provenientes de Asia (representada por China, la India, Indonesia y la República de Corea), las elasticidades-ingreso de los Estados Unidos de América solo se ven superadas por las que se registran en el comercio intrarregional Sur-Sur dentro de Asia. Por otra parte, ciertos segmentos del comercio Sur-Sur se caracterizan por elasticidades-ingreso relativamente altas, sobre todo en el caso de los flujos comerciales dirigidos a Asia. Los importadores asiáticos, de hecho, tienen mayores elasticidades-ingreso para las importaciones provenientes de otros países asiáticos en comparación con los importadores del Norte Global (la zona del euro y los Estados Unidos de América) y los socios comerciales extrarregionales en el Sur Global (América del Sur). Además, la elasticidad-ingreso media (no ponderada) de la demanda de importaciones de América del Sur es superior para los importadores asiáticos que para la zona del euro (mientras que es inferior para los Estados Unidos de América, el otro importador clave del Norte). En otras palabras, Asia es un destino bastante atractivo (en términos de elasticidades de las importaciones) en el comercio Sur-Sur, tanto intrarregional como interregional.
Esto no es igual en el caso de América del Sur, donde las elasticidades-ingreso para el comercio intrarregional son mayores que para las importaciones de la zona del euro provenientes de América del Sur, pero menores que para las importaciones asiáticas —y especialmente las estadounidenses - de productos sudamericanos. Asimismo, para los socios comerciales en Asia, América del Sur es un destino menos atractivo (en términos de elasticidades-ingreso de la demanda de importaciones) que los mercados del Norte.

Estos resultados tienen algunas importantes implicancias. Por una parte, indican que el fortalecimiento de los lazos comerciales con otros países del Sur Global podría resultar beneficioso para que los países en desarrollo puedan lograr la diversificación de las fuentes de crecimiento y los mercados de exportación, así como un desarrollo más estable y sostenible. Refuerzan esta idea el reciente desempeño exportador de los países en desarrollo (véanse los gráficos 1 y 2) y las predicciones sobre su expansión y la demanda de importaciones (véanse el gráfico 3 y el cuadro 3). En el gráfico 3 se muestran las proyecciones de crecimiento económico y se verifica lo que es un consenso entre los economistas: que las economías emergentes y en desarrollo crecerán considerablemente más rápido en el futuro próximo que las economías avanzadas. En el cuadro 3 se respalda esta predicción al especificar las predicciones de aumento del PIB real por parte del Fondo Monetario Internacional (FMI) para diversos países del Norte Global y del Sur Global. Tanto en el gráfico 3 como en el cuadro 3, se indica que en los próximos años los países en desarrollo, y en especial los de Asia, superarán —en algunos casos por un amplio margen - a los países industrializados en términos de crecimiento económico. Según las predicciones del FMI, de 2015 a 2019, las tasas de actividad económica serán, en promedio, alrededor de dos veces más elevadas en las economías emergentes y en desarrollo que en las economías avanzadas. Mientras que se prevé que el PIB real aumente a tasas anuales de entre tan solo $1,46 \%$ y $1,54 \%$ en la zona del euro y de entre $2,22 \%$ y $3,03 \%$ en los Estados Unidos de América, las predicciones de crecimiento para las mayores potencias del Sur, como China o la India, llegan a 7,28\% y 6,77\%, 
GRÁFICO 3

Agrupaciones de países seleccionadas: predicciones de crecimiento del PIB real y las importaciones, 2016-2020

(En porcentajes)

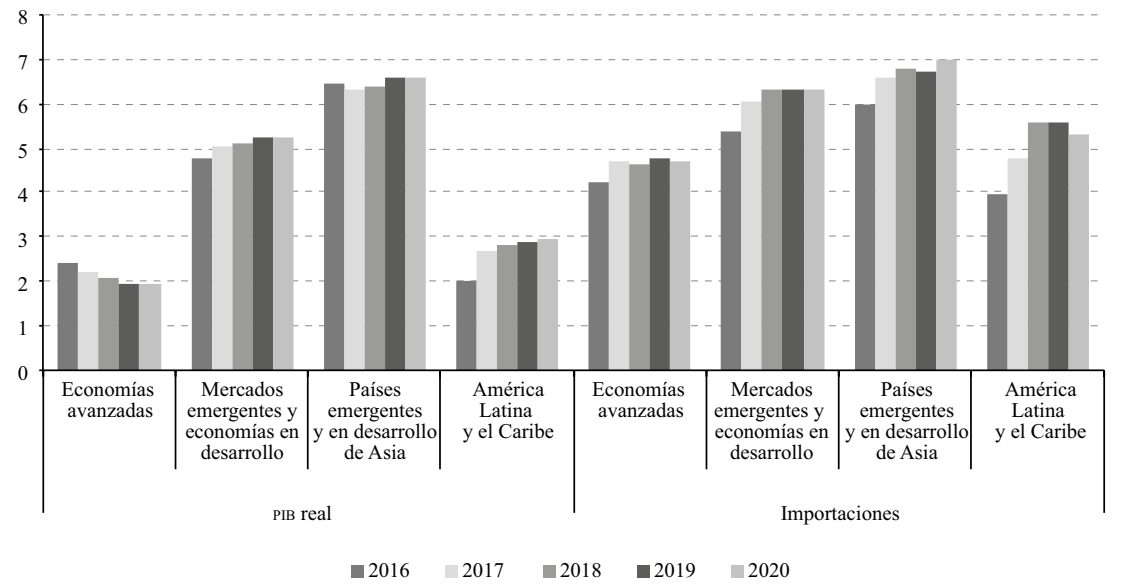

Fuente: Elaboración propia sobre la base de datos del Fondo Monetario Internacional (FMI), Perspectivas de la Economía Mundial, abril de 2015.

CUADRO 3

Países seleccionados: predicciones de crecimiento del PIB real, 2015-2019 (En porcentajes)

\begin{tabular}{|c|c|c|c|c|c|c|}
\hline País & 2015 & 2016 & 2017 & 2018 & 2019 & Promedio \\
\hline Argentina & 1,00 & 1,50 & 2,00 & 2,00 & 2,00 & 1,70 \\
\hline Brasil & 2,65 & 3,00 & 3,15 & 3,34 & 3,51 & 3,13 \\
\hline Chile & 4,05 & 4,23 & 4,50 & 4,50 & 4,50 & 4,36 \\
\hline China & 7,28 & 6,97 & 6,76 & 6,63 & 6,52 & 6,83 \\
\hline India & 6,35 & 6,48 & 6,65 & 6,73 & 6,77 & 6,60 \\
\hline Indonesia & 5,80 & 6,00 & 6,00 & 6,00 & 6,00 & 5,96 \\
\hline República de Corea & 3,80 & 3,78 & 3,82 & 3,75 & 3,76 & 3,78 \\
\hline Perú & 5,81 & 5,80 & 5,80 & 5,81 & 5,80 & 5,80 \\
\hline Zona del euro & 1,46 & 1,54 & 1,54 & 1,53 & 1,53 & 1,52 \\
\hline Japón & 0,97 & 0,67 & 0,99 & 1,01 & 1,13 & 0,95 \\
\hline Estados Unidos de América & 2,95 & 3,03 & 2,91 & 2,59 & 2,22 & 2,74 \\
\hline
\end{tabular}

Fuente: Elaboración propia sobre la base de datos del Fondo Monetario Internacional (FMI), Perspectivas de la Economía Mundial, abril de 2015 .

respectivamente. Como se denota en el cuadro 3, las perspectivas de crecimiento para los países industrializados se ubican por debajo de las de casi todos los países en desarrollo aquí considerados (con la excepción de la Argentina, donde la perspectiva de crecimiento ha sido revisada muy a la baja recientemente) respecto de cada año para el que se dispone de predicciones. Esto tiene relevantes consecuencias en relación con la demanda de importaciones: es esperable que los países o las regiones de mayor crecimiento muestren también una búsqueda más dinámica de importaciones. Como puede observarse en el gráfico 3 , con respecto a los próximos años se proyecta que el crecimiento de las importaciones en los países en desarrollo permanezca relativamente estable, registrando diferencias que oscilarían entre 1 y 1,6 puntos porcentuales por sobre el de economías avanzadas. Allí donde coinciden con mayores elasticidades-ingreso, estas tasas más elevadas de aumento de las importaciones indican que los posibles efectos de derrame de la actividad económica (spillovers) de un país del Sur a otro país del Sur son mayores que los registrados en las relaciones Sur-Norte. 
Si bien las cifras incluidas anteriormente indican decididamente que persistirán las diferencias de crecimiento entre el Sur y el Norte (tanto en términos de actividad económica como de importaciones), hay que tener en cuenta dos factores relevantes. En primer lugar, estas son solo predicciones y las cifras de crecimiento pueden resultar peores que lo esperado. En efecto, algunos observadores, como la CEPAL (2014), son menos optimistas y señalan que el mundo ha ingresado en un nuevo período de lento crecimiento que puede proseguir durante un tiempo. Los continuos cambios en la economía mundial, sobre todo en el modelo de crecimiento de China de exportaciones a demanda interna (que han reducido su demanda de importaciones y su papel como motor del crecimiento para otros países), pueden afectar a las elasticidades de la demanda de importaciones. En segundo término, es conveniente recordar la diferencia entre niveles y tasas de cambio. Si las diferencias en los niveles de base (de ingreso e importaciones) entre dos países importadores es lo suficientemente grande, el incremento de las importaciones generado por un aumento del ingreso en el país importador del Norte puede, en términos absolutos, superar el incremento de las importaciones generadas por un aumento del ingreso en el país importador del Sur. Incluso si las elasticidades-ingreso y las tasas de crecimiento de la importaciones para la relación comercial Sur-Sur son más elevadas que para la relación Sur-Norte. Si bien esto se aplica a varias de las relaciones comerciales bilaterales analizadas con anterioridad, el razonamiento expuesto en la última sección pone énfasis en la diferencia de dinámica entre el Sur y el Norte cuando evalúa — desde una perspectiva de políticas - la promesa que conlleva la expansión del comercio Sur-Sur para el desarrollo económico de los países involucrados.

\section{VIII}

\section{Consecuencias en materia de políticas y reflexiones finales}

En este artículo se han planteado algunas consideraciones teóricas para reforzar los vínculos del comercio Sur-Sur, en particular en el contexto del estancamiento económico generalizado en el Norte Global y las lecciones que dejó la reciente crisis económica mundial. También se ha documentado la evolución dinámica del comercio SurSur en las últimas décadas y se han presentado algunos indicios de que este dinamismo probablemente continúe en el futuro, superando incluso a los flujos comerciales que involucran a las economías avanzadas. El análisis econométrico de este documento - centrado en los flujos comerciales que atañen a una muestra de países de Asia y América del Sur y dos mercados clave del Norte (la zona del euro y los Estados Unidos de América)produjo resultados variados en relación con la pregunta de si el comercio Sur-Sur generalmente se caracteriza por mayores elasticidades-ingreso de la demanda de importaciones que el comercio Sur-Norte. Mientras que las elasticidades-ingreso de la demanda de importaciones relativamente altas convierten a los países en desarrollo de Asia en un atractivo destino para el comercio SurSur, tanto intrarregional como interregional, no ocurre lo mismo con América del Sur. La actividad económica en los Estados Unidos de América, uno de los mercados clave del Norte, se caracteriza por elasticidades-ingreso comparativamente elevadas respecto de las importaciones provenientes del Sur Global, especialmente de América del Sur, superando en muchos casos las estimaciones de elasticidad-ingreso para las relaciones comerciales Sur-Sur. Sin embargo, esto no es igual en la zona del euro, donde el crecimiento del ingreso real solo genera aumentos relativamente modestos de las importaciones provenientes de los países de Asia y América del Sur aquí estudiados.

En términos de políticas, los resultados indican que los países en desarrollo deben procurar fortalecer y expandir las relaciones comerciales con otros países similares en desarrollo y eliminar los obstáculos al comercio Sur-Sur. En consecuencia, Fugazza y Vanzetti (2008) encuentran que el énfasis en obtener acceso a los mercados del Norte representa una oportunidad perdida para los países en desarrollo, ya que las posibles ganancias derivadas de la eliminación de los obstáculos al comercio Sur-Sur son muy superiores (véase también Anderson y Strutt, 2011). La principal razón para estas posibles ganancias radica en que debido a la similitud 
de sus etapas de desarrollo y niveles de competitividad, los países involucrados no deben preocuparse de verse abrumados por las importaciones tras la liberalización del comercio. La UNCTAD (2008, pág. xviii) plantea un argumento semejante cuando sostiene que los acuerdos de comercio regional Sur-Sur pueden formar parte de un escenario estratégico para acrecentar las ganancias económicas de los países en desarrollo. Los aranceles, así como otros obstáculos al comercio y de infraestructura, suelen ser mayores para el comercio Sur-Sur que para los flujos comerciales Sur-Norte, de modo que aún hay bastante margen para facilitar los flujos comerciales entre los países en desarrollo. La liberalización y facilitación del comercio Sur-Sur puede, por lo tanto, fortalecer aún más los vínculos económicos entre los países del Sur y, de hecho, en los últimos años han aumentado considerablemente los acuerdos de libre comercio entre países en desarrollo (Wignaraja, Ramizo y Burmeister, 2012). Athukorala (2011, pág. 44) sostiene que, más que competir con el comercio Sur-Norte, el comercio Sur-Sur lo complementa, lo que reafirma el argumento de que procurar expandir el comercio Sur-Sur es una estrategia razonable para los encargados de la formulación de políticas en los países en desarrollo. Al mismo tiempo, dichos encargados deben hacer lo posible para diversificar e incrementar el contenido tecnológico del comercio SurSur, a fin de maximizar los dividendos del desarrollo. Esto es especialmente importante en los países de América del Sur, cuyas exportaciones a Asia suelen concentrarse en unos pocos productos básicos, lo que genera cierta vulnerabilidad y limita la contribución de las exportaciones a la industrialización de alta tecnología, la creación de empleo y el mayor desenvolvimiento económico.

La evidencia y los argumentos aquí presentados ofrecen ciertas bases teóricas y empíricas para este tipo de recomendaciones de políticas. Como se ha visto, tanto el crecimiento económico como el comercio internacional prometen ser más dinámicos en el hemisferio en desarrollo que en el mundo industrializado. Además, para repetir el resultado central del análisis econométrico realizado en este trabajo respecto de algunos segmentos y ciertas relaciones comerciales bilaterales —en especial las que involucran a países asiáticos-, el comercio Sur-Sur se caracteriza por mayores elasticidades-ingreso que la demanda de importaciones del Norte. En estos casos, los mayores incrementos del ingreso en los países importadores del Sur también beneficiarán a sus socios comerciales del Sur, quienes verán aumentar la demanda de sus exportaciones. Es decir, este crecimiento será más rápido en caso de que los ingresos en sus mercados de exportación del Norte aumenten al mismo ritmo que en los países importadores del Sur. También es probable que esta relación se fortalezca aún más si gradualmente se eliminan los obstáculos al comercio Sur-Sur.

En conjunto, estos resultados indican que las recompensas por promover la integración Sur-Sur a menudo pueden ser superiores a las obtenidas a raíz de una mayor profundización de las relaciones comerciales Sur-Norte. Los resultados de esta investigación muestran que la promoción del comercio Sur-Sur puede ser una opción sensata y viable que permita a los países en desarrollo encontrar en el comercio exterior una fuente más prometedora y sostenible para su crecimiento económico. No obstante, es necesario realizar nuevas investigaciones para corroborar y refinar estos resultados, por ejemplo, entre países y regiones. En especial, se deben llevar a cabo análisis similares para una muestra más grande de países que también incluya los flujos comerciales Sur-Sur con intervención de economías africanas. La solidez de los resultados empíricos debe probarse aún más mediante la aplicación de distintos métodos de estimación. El comercio y la cooperación Sur-Sur han recibido una renovada atención en los últimos años y cabe esperar que se mantengan en los primeros lugares de la agenda de los encargados de la formulación de políticas en los países en desarrollo, de manera que cualquier análisis empírico adicional será bienvenido para la adopción de decisiones sobre la evidencia. 
ANEXO A

Los datos de importación se obtuvieron de la Oficina de Análisis Económicos para los Estados Unidos de América y de la Dirección de Estadísticas Comerciales del FMI para la zona del euro y los ocho países en desarrollo de nuestra muestra. Los datos sobre los tipos de cambio y los deflactores del PIB o, en su defecto, los índices de precios al consumidor (IPC) se tomaron de la base de datos de Estadísticas Financieras Internacionales del FMI, al tiempo que los datos del PIB se obtuvieron de las

ANEXO B

\section{Proceso de estimación}

El primer paso en la estimación de los coeficientes para cada relación comercial bilateral consistió en realizar una regresión en la ecuación completa:

$$
\begin{gathered}
\Delta M_{t}^{j}=\alpha+\sum_{i=1}^{n} \beta_{i} \Delta \ln Y_{t-i}+\sum_{i=1}^{n} \gamma_{i} \Delta \ln E_{t-i}^{j} \\
+\sum_{i=1}^{n} \delta_{i} \Delta \ln E_{t-i}^{j}+v_{1} \ln Y_{t-1}+v_{2} \ln E_{t-1}^{j} \\
+v_{3} \ln M_{t-1}^{j}+\epsilon_{t}
\end{gathered}
$$

donde $l n$ es la forma logarítmica natural, $M$ es la demanda real de importaciones del país $j, Y$ es el ingreso nacional real, $E$ es el tipo de cambio bilateral real entre el país de origen y el país $j$ en el momento $t$ (definido como la cantidad de unidades de moneda local por unidad de moneda extranjera ajustada para niveles de precio nacional y extranjero) y $\varepsilon_{t}$ es el término de error aleatorio. El segundo paso consistió en un proceso reiterativo de eliminación de las variables diferenciadas estadísticamente insignificantes, manteniendo las variables de nivel retardadas. En un tercer paso, se realizó una prueba $F$ para restricciones lineales en el modelo final, verificando si los coeficientes para las variables de nivel retardadas para $Y, E$ y $M$, que constituyen la denominada "corrección de error retardado", eran igual a cero (esto
Perspectivas de la economía mundial y la base de datos de Estadísticas Financieras Internacionales del FMI, así como de la base de datos estadísticos de la OCDE (OECD. Stat). Todos los datos son trimestrales. La cantidad de observaciones varía de 43 a 206 para las distintas estimaciones del comercio bilateral (véase el anexo C). El período de tiempo cubierto va de mediados de la década de 1990 a 2011 o 2012, pero, en algunos casos, la información data incluso de los años cuarenta. es, si el término $v_{1}=v_{2}=v_{3}=0$ ). Los resultados de estas pruebas $\mathrm{F}$ se incluyen en los cuadros del anexo $\mathrm{C}$ y ayudaron a decidir si se debía mantener el término de corrección de error retardado o había que excluirlo de la ecuación. Pesaran, Shin y Smith (2001, pág. 300) proporcionan límites de valor crítico para el estadístico F. Si el estadístico F es mayor que el límite de valor crítico, la hipótesis nula de $v_{1}=v_{2}=v_{3}=0$ es rechazada (las variables de nivel retardadas son cointegradas). En el cuadro CI(iii) de su artículo, Pesaran, Shin y Smith (2001, pág. 300) especifican que los límites de valor crítico para el caso con tres variables en el término de corrección de error retardado son 3,77 a nivel del 10\%, 4,35 a nivel del 5\%, 4,89 a nivel del 2,5\% y 5,61 a nivel del $1 \%$, respectivamente. Al comparar los resultados de las pruebas $\mathrm{F}$ con estos valores críticos, se decidió caso por caso mantener o excluir los términos de corrección de error retardado de la ecuación. En caso de mantener el término de corrección de error retardado, el coeficiente para la variable de nivel retardada para $Y$ —esto es, $v_{1}$ — ofrece el "equilibrio" a largo plazo en la elasticidad-ingreso de la demanda de importaciones para la relación comercial bilateral en cuestión. Sin embargo, si el término de corrección de error retardado debe excluirse (de conformidad con el estadístico F), solo se obtiene el efecto a corto plazo de un cambio en el ingreso sobre la demanda de importaciones.

\section{Bibliografía}

Amsden, A. (1987), "The directionality of trade: historical perspective and overview", Exports of Developing Countries: How Direction Affects Performance, O. Havrylyshyn, Washington, D.C., Banco Mundial.
Anderson, K. y A. Strutt (2011), "Asia's changing role in world trade: prospects for South-South trade growth to 2030", $A D B$ Economics Working Paper Series, $\mathrm{N}^{\circ} 264$, Manila, Banco Asiático de Desarrollo. 
Athukorala, P. (2011), "South-South trade: an Asian perspective", ADB Economics Working Paper Series, $\mathrm{N}^{\circ} 265$, Manila, Banco Asiático de Desarrollo.

Bahmani-Oskooee, M. y O. Kara (2005), "Income and price elasticities of trade: some new estimates", The International Trade Journal, vol. 19, $\mathrm{N}^{\circ}$ 2, Taylor \& Francis.

Bahmani-Oskooee, M., G.G. Goswamil y B.K. Talukdar (2005), "Exchange rate sensitivity of the Canadian bilateral inpayments and outpayments", Economic Modelling, vol. 22, $\mathrm{N}^{\circ} 4$, Amsterdam, Elsevier.

Banco Mundial (2011), Global Development Horizons 2011. Multipolarity: The New Global Economy, Washington, D.C.

BASD (Banco Asiático de Desarrollo) (2011), Asian Development Outlook 2011. South-South Economic Links, Manila.

CEPAL (Comisión Económica para América Latina y el Caribe) (2014), Balance Preliminar de las Economías de América Latina y el Caribe 2014 (LC/G.2632-P), Santiago.

Chang, T., Y. Ho y Ch. Huang (2005), "A reexamination of South Korea's aggregate import demand function: the bounds test analysis", Journal of Economic Development, vol. 30, $\mathrm{N}^{\circ} 1$.

Chatelain, J.-B. y A. Tiomo (2001), "Investment, the cost of capital and monetary policy in the nineties in France: a panel data investigation", Working Paper Series, $N^{\circ}$ 106, Banco Central Europeo.

Dahi, O. y F. Demir (2008), "South-South trade in manufactures: current performance and obstacles for growth", Review of Radical Political Economics, vol. 40, $\mathrm{N}^{\circ} 3$, SAGE.

Debelle, G. y J. Vickery (1998), "The macroeconomics of Australian unemployment", Unemployment and the Australian Labour Market, G. Debelle y J. Borland (eds.), Keswick, Alken Press.

FMI (Fondo Monetario Internacional) (2011), "New Growth Drivers for Low-Income Countries: The Role of BRICs" [en línea] https://www.imf.org/external/np/pp/eng/2011/011211.pdf.

Fugazza, M. y D. Vanzetti (2008), "A South-South survival strategy: the potential for trade among developing countries", The World Economy, vol. 31, $\mathrm{N}^{\circ}$ 5, Wiley.

Goldstein, M. y M. Khan (1985), "Income and price effects in foreign trade", Handbook of International Economics, R. Jones y P. Kenen (eds.), vol. 2, Amsterdam, North-Holland.

Griffith-Jones, S. y J.A. Ocampo (2009), "The financial crisis and its impact on developing countries", Working Paper, $\mathrm{N}^{\circ} 53$, Brasilia, Centro Internacional de Políticas para el Crecimiento Inclusivo.

Grullón, S. (2012), "Price and income elasticities of disaggregated import demand: bounds test results for the Dominican Republic", Journal of Economics and Sustainable Development, vol. $3, \mathrm{~N}^{\circ} 4$.

Hanson, G. (2012), "The rise of middle kingdoms: emerging economies in global trade", Journal of Economic Perspectives, vol. 26, $\mathrm{N}^{\circ} 2$, Nashville, Tennessee, American Economic Association.

Kaplinsky, R. y M. Farooki (2010), "Global value chains, the crisis, and the shift of markets from North to South", Global Value Chains in a Postcrisis World: A Development Perspective, O. Cattaneo y otros (eds.), Washington, D.C., Banco Mundial.

Kaplinsky, R., A. Terheggen y J. Tijaja (2010), "What happens when the market shifts to China? The Gabon timber and Thai Cassava value chains", Global Value Chains in a Postcrisis World: A Development Perspective, O. Cattaneo y otros (eds.), Washington, D.C., Banco Mundial.

Klinger, B. (2009), "Is South-South trade a testing ground for structural transformation?", Policy Issues in International Trade and Commodities Study Series, $\mathrm{N}^{\circ} 40$, Nueva York, Conferencia de las Naciones Unidas sobre Comercio y Desarrollo (UNCTAD).

Kwack, S.Y. y otros (2005), "Consistent estimates of world trade elasticities and an application to the effects of Chinese Yuan (RMB) appreciation", Journal of Asian Economics, vol. 18, $\mathrm{N}^{\circ} 2$, Amsterdam, Elsevier.
Lall, S. (1987), "India's economic relations with the South", Exports of Developing Countries: How Direction Affects Performance, O. Havrylyshyn (ed.), Washington, D.C., Banco Mundial.

Lewis, W.A. (1980), "The slowing down of the engine of growth", American Economic Review, vol. 70, $\mathrm{N}^{\circ} 4$, Nashville, Tennessee, American Economic Association.

Milberg, W. y D. Winkler (2010), "Trade, crisis, and recovery: restructuring global value chains", Global Value Chains in a Postcrisis World: A Development Perspective, O. Cattaneo y otros (eds.), Washington, D.C., Banco Mundial.

Myrdal, G. (1956), An International Economy. Problems and Prospects, Londres, Routledge.

Ocampo, J.A. (2009), "Latin America and the global financial crisis", Cambridge Journal of Economics, vol. 33, $\mathrm{N}^{\circ} 4$, Oxford University Press.

ONUDI (Organización de las Naciones Unidas para el Desarrollo Industrial) (2006), Industrial Development, Trade and Poverty Reduction through South-South Cooperation, Viena.

Panopoulou, E. y N. Pittis (2004), "A comparison of autoregressive distributed lag and dynamic oLs cointegration estimators in the case of a serially correlated cointegration error", The Econometrics Journal, vol. 7, $\mathrm{N}^{\circ} 2$, Wiley.

Pesaran, M.H. e Y. Shin (1999), "An autoregressive distributed lag modelling approach to cointegration analysis", Econometrics and Economic Theory in 20th Century: The Ragnar Frisch Centennial Symposium, S. Strom (ed.), Cambridge, Cambridge University Press.

Pesaran, M.H., Y. Shin y R. Smith (2001), "Bounds testing approaches to the analysis of level relationships", Journal of Applied Econometrics, vol. 16, $\mathrm{N}^{\circ} 3$, Wiley.

PNUD (Programa de las Naciones Unidas para el Desarrollo) (2013), Informe sobre Desarrollo Humano 2013. El ascenso del Sur: progreso humano en un mundo diverso, Nueva York.

Shaffaeddin, M. (2008), "South-South regionalism and trade cooperation in the Asia-Pacific region", RCC Policy Paper Series, Colombo, Centro Regional del PNUd en Colombo.

Shirotori, M. y A.C. Molina (2009), South-South Trade: The Reality Check, Ginebra, Conferencia de las Naciones Unidas sobre Comercio y Desarrollo (UNCTAD).

Stock, J.H. y M.W. Watson (1993), "A simple estimator of cointegrating vectors in higher order integrated systems", Econometrica, vol. 61, $\mathrm{N}^{\circ} 4$, Nueva York, The Econometric Society.

Thorbecke, W. y G. Komoto (2010), "Investigating the effect of exchange rate changes on transpacific rebalancing", $A D B I$ Working Paper, $\mathrm{N}^{\circ}$ 247, Tokio, Instituto del Banco Asiático de Desarrollo.

UNCTAD (Conferencia de las Naciones Unidas sobre Comercio y Desarrollo) (2011), The Least Developed Countries Report 2011 (UNCTAD/LDC/2011), Nueva York.

(2010), Economic Development in Africa Report 2010. South-South Cooperation: Africa and the New Forms of Development Partnership (UNCTADC/ALDC/AFRICA/2010), Nueva York.

(2008), South-South Trade in Asia: The Role of Regional Trade Agreements (UNCTAD/DITC/TAB/MISC/2008/2), Ginebra. (2005), Informe sobre el comercio y el desarrollo 2005, Nueva York.

Uz, I. (2010), "Bilateral trade elasticities of Turkey", International Journal of Applied Economics, vol. 7, $\mathrm{N}^{\circ} 1$.

Wignaraja, G., D. Ramizo y L. Burmeister (2012), "Asia-Latin America Free Trade Agreements: an instrument for interregional liberalization and integration?", ADBI Working Paper, $\mathrm{N}^{\circ} 382$, Tokio, Instituto del Banco Asiático de Desarrollo.

Yin, F. y S. Hamori (2011), "Estimating the import demand function in the autoregressive distributed lag framework: the case of China", Economics Bulletin, vol. 31, № 2 . 